\title{
Plant And Soil Microbial Communities Regulate Soil Respiration In Response To Precipitation And Land Use In An Inner Mongolian Grassland
}

\section{Chi Zhang}

Inner Mongolia University

Chao Song

Michigan State University

Donghui Wang

Inner Mongolia University

Wenkuan Qin

Peking University

Biao Zhu

Peking University

Frank Yonghong Li

Inner Mongolia University

Yonghui Wang ( $\nabla$ yhwang@imu.edu.cn )

Inner Mongolia University https://orcid.org/0000-0002-3351-4134

Wenhong Ma

Inner Mongolia University

\section{Research Article}

Keywords: Climatic change, Climate-carbon model, Heterotrophic respiration, Autotrophic respiration, Inner Mongolian grassland

Posted Date: November 17th, 2021

DOI: https://doi.org/10.21203/rs.3.rs-1070086/v1

License: (c) (i) This work is licensed under a Creative Commons Attribution 4.0 International License. Read Full License 


\section{Abstract}

Purpose: Changes in precipitation amount and land use are expected to greatly impact soil respiration $\left(R_{S}\right)$ of grassland ecosystems. However, little is known about whether they can interactively impact $R_{S}$ and how plant and soil microbial communities regulate the response of $R_{S}$.

Methods: Here, we investigated the impacts of altered precipitation amount ( $-50 \%$, ambient and $+50 \%)$ and land-use regime (fencing, mowing and grazing) on $\mathrm{R}_{\mathrm{s}}$ with a field experiment in the Inner Mongolian grassland.

Results: We found that altered precipitation amount impacted $\mathrm{R}_{\mathrm{S}}$ and its components across the 3-year study period, while land-use regime alone or its interaction with precipitation amount impacted them in certain years. In addition, changed soil microclimate, especially soil moisture, under altered precipitation amount and land-use regime can impact the components of $R_{s}$ either directly or indirectly via influencing plant and soil microbial communities.

Conclusions: Integrating changing precipitation amount and land-use regime within experiment can produce more accurate insights into grassland $\mathrm{R}_{\mathrm{S}}$, and chronically shifted plant and soil microbial communities under these changes may result in distinct long-term impacts on $R_{s}$.

\section{Introduction}

Grasslands comprise approximately one third of the earth's land surface and account for $20 \%$ of carbon in soil and vegetation globally (Piao et al. 2009; Zhou et al. 2017). Soil respiration in temperate and tropical grasslands releases 390 and $601 \mathrm{~g} \mathrm{C} \mathrm{m}^{-2}$ annually to the atmosphere (Wang and Fang 2009), making grassland $R_{S}$ a crucial part of the global $R_{s}$. Climate and land use changes are expected to profoundly influence grassland $R_{S}$ (IPCC 2013). In particular, changing precipitation will likely have substantial impacts on grassland soil respiration as grassland soil is typically under water deficit (Liu et al. 2009, 2016; Hashimoto et al. 2015). In addition, most grassland ecosystems are subjected to diverse and intensive anthropogenic activities, such as grazing, mowing, and other land-use regimes (Liu et al. 2012; Han et al. 2012; Gossner et al. 2016). These land-use regimes can change $R_{S}$ via influencing the abiotic and biotic environment, e.g. soil microclimates (Gong et al. 2014; Tang et al. 2019) and growth rates of plants and soil microbes (Bagchi and Ritchie 2010; Hou et al. 2014; Gong et al. 2014; Wang et al. $2020 \mathrm{~d}$ ). Impacts of changing precipitation and land-use regimes on grassland $\mathrm{R}_{\mathrm{s}}$ could feedback to climate change and thus have significant global consequences.

In grassland ecosystems, grazing and mowing are widely used management practices and can strongly impact $R_{S}$ (Cao et al. 2004; Jia et al. 2006, 2007). For example, experimental studies and syntheses have shown that $R_{S}$ often decreases with grazing intensity (Cao et al. 2004; Tang et al. 2019; Wang et al. 2017). Similarly, studies have also shown significantly reduced $R_{s}$ under mowing (Wan and Luo 2003; Wan et al. 
2005) or even a lower $R_{s}$ under mowing than under grazing (Koncz et al. 2015). However, because grazing and mowing may affect $R_{s}$ via processes that are climate dependent, such as changing plant biomass or altering abiotic conditions, the effects of grazing and mowing may depend on climatic conditions. For example, grazing or mowing may influence soil moisture and consequently affect $R_{S}$, but such effects may be stronger in arid regions than in humid regions (Wang et al. 2020d; Han et al. 2012). As a result, understanding the grazing and mowing effects on $R_{s}$ in grassland requires consideration of the potential interactive effect of climate and land use regime (Xu et al. 2015; Wang et al. 2020d).

Changes in precipitation and land use regime may interact because they both influence many of the same abiotic and biotic drivers of $R_{S}$. Observational (Geng et al. 2012), experimental (Liu et al. 2018), and synthetic (Tang et al. 2019) studies have shown that reduced precipitation (Ren et al. 2017; Zhou et al. 2018; Zhong et al. 2019) and intensive grazing and mowing (Jing et al. 2014; Musiał et al. 2020; Tang et al. 2019) can both negatively impact plants and soil microbes and alter their community composition, such as reducing plant and soil microbial diversities (Ma et al. 2017; Bardgett et al. 2001). The altered plant and soil microbial communities can in turn affect the $R_{S}$ by changing substrate supply to plant roots and soil microbes (Xu et al. 2015; Wang et al. 2020d). Disentangling how precipitation and land use regime affect these interacting biotic drivers is key to predicting soil carbon fluxes in the future.

The Inner Mongolian grassland, part of the Eurasian grassland biome (Han et al. 2009; Niu et al. 2010; Lu et al. 2015), is an ideal system to study the interactive effects of land use and precipitation on soil carbon cycling. Grazing and mowing are widely practiced land-use regimes (Lu et al. 2015; Wang et al. 2020a) and precipitation is often considered the most important climatic driver of $R_{S}$ in Inner Mongolian grasslands (Yang et al. 2020; Li et al. 2020). During the last decades, this region has been experiencing more intensive grazing and mowing (Wu et al. 2015; Li et al. 2018; Wang et al. 2020a) as well as reduced but more variable precipitation (Piao et al. 2010, Huang et al. 2015). While previous work in this region has examined the effects of land use and precipitation individually, it remains unclear how land use and precipitation may interact to affect soil respiration (Gong et al. 2014; Yang et al. 2020). Here, we performed an in situ experiment with altered precipitation and land use regimes (i.e. mowing and grazing, Figure S1) to investigate their interactive effects on $R_{S}$ and its components. We also quantified soil microclimate, plant and soil microbial communities to elucidate the mechanisms through which the interactive effects occur.

\section{Materials And Methods}

Study site

Our study was conducted at the Maodeng Grassland Ecosystem Research Station of Inner Mongolia University ( $44^{\circ} 10^{\prime} \mathrm{N}, 116^{\circ} 28^{\prime} \mathrm{E}, 1101 \mathrm{~m}$ a.s.l.) located in the Xilingol region of Inner Mongolia, China (Figure S1a). This area has a temperate semi-arid climate, with a short and cool growing-season (normally starts in May and ends in October). During the 3 years of study (2017-2019), the mean growing-season and annual air temperature was $10.7^{\circ} \mathrm{C}$ and $-1.2^{\circ} \mathrm{C}$, respectively. Annual growing- 
season precipitation ranged from 144 to $252 \mathrm{~mm} \mathrm{yr}^{-1}$ and accounted for $\sim 90 \%$ of total annual precipitation (ranged from 168-278 mm, Figure S2). The natural vegetation is a typical steppe dominated by perennial grasses such as Leymus chinensis, Stipa baicalensis and Cleistogenes squarrosa. Soil developed is a Calcic-Orthic Aridisol according to the US soil taxonomy classification system with a mean pH of 8.1 at $0-20 \mathrm{~cm}$ soil depth (Wang et al. 2020b).

\section{Experimental design}

We established a field experiment with treatments of precipitation amount and land-use regime using a randomized complete block design with split plot (Figure S1b). Within each block, we arranged land use treatments in plots and precipitation amount treatments in subplots. Specifically, in 2011, we established three $100 \mathrm{~m} \times 100 \mathrm{~m}$ blocks with $3 \mathrm{~m}$ in between. Each block was divided into nine $33.3 \mathrm{~m} \times 33.3 \mathrm{~m}$ plots. We applied three land use treatments to each block with 3 plots randomly chosen for each treatment. The three land use treatments are no grazing or mowing (wire fence enclosure), grazing (with 6 sheep in July and August, once per month until residual height of plants reached $6 \mathrm{~cm}$ ), and mowing (to $6 \mathrm{~cm}$, once per year in August). The intensity of grazing and mowing treatments in our experiment represented a moderate land-use intensity in this region (Baoyin et al. 2014). In 2016, we established precipitation amount treatments at the end of the growing season. Briefly, three $3 \mathrm{~m} \times 5 \mathrm{~m}$ subplots with $2 \mathrm{~m}$ in between were established within each plot and each subplot was randomly assigned to one of the three precipitation treatments. Consistent with a network of world-wide precipitation amount manipulation experiments (www.drought-net.org), we implemented three levels of precipitation treatment: $50 \%$ reduction (Dry), ambient (Amb), and 50\% increase (Wet). Reduction in precipitation was achieved by installing ten transparent Panlite sheet channels over the subplot $(25 \mathrm{~cm}$ wide and $340 \mathrm{~cm}$ long). These channels were installed at a $\sim 10^{\circ}$ angle above each subplot and covered $50 \%$ of its area, resulting in removing $50 \%$ of rainwater (Figure S1b). Removed rainwater was collected and immediately sprinkled to a wet treatment subplot within the same plot after the rain event, resulting in adding $50 \%$ of rainwater. During growing seasons of the 3-year study period (2017-2019), the amounts of precipitation received by subplots of these precipitation treatments ranged from $68-378 \mathrm{~mm}$, representing $75 \%$ of the range observed during the last 10 years under natural condition (ranged from 136-454 mm) (Figure 1).

\section{Soil respiration measurement}

We manually measured $R_{s}$ biweekly in each subplot. $R_{s}$ was measured with a LI-8100 Automated Soil $\mathrm{CO}_{2}$ Flux systems (Li-Cor Inc., Lincoln, NE, USA) on a shallow polyvinyl chloride (PVC) collar $(20 \mathrm{~cm}$ in diameter and $10 \mathrm{~cm}$ in height) installed to a soil depth of $5 \mathrm{~cm}$. We also partitioned the $\mathrm{R}_{\mathrm{s}}$ into heterotrophic $\left(R_{h}\right)$ and autotrophic $\left(R_{a}\right)$ components. Heterotrophic respiration was measured by installing a deep PVC collar (20 cm in diameter and $45 \mathrm{~cm}$ in height) to a soil depth of $40 \mathrm{~cm}$ and removing all above-ground vegetation inside these collars. The installation depth is sufficient to exclude most organic matter input from plants because $>80 \%$ of the belowground biomass is distributed in the top $30 \mathrm{~cm}$ (Figure S3). Because installing deep collars could artificially increase dead roots input into soil and thus influence $R_{h}$, we installed these deep collars 9 months prior to $R_{h}$ measurements to eliminate 
experimental artifacts (Zhou et al. 2007; Wang et al. 2020c). Autotrophic respiration was calculated as the difference between $R_{s}$ and $R_{h}$. Concurrent with soil respiration measurements, we measured soil temperature (ST) and moisture (SM) at $5 \mathrm{~cm}$ depth using 6000-09TC and GS-1 probes attached to the LI8100. We also obtained daily air temperature and precipitation from a nearby weather station $(\sim 100 \mathrm{~m})$.

\section{Plant and soil sampling}

We measured the aboveground (ANPP) and belowground (BNPP) net primary productivities with a harvest method and a root ingrowth-core method (Xu et al. 2015; Liu et al. 2018), respectively. To measure ANPP, we prepared three $1 \mathrm{~m} \times 1 \mathrm{~m}$ quadrats in each subplot and randomly selected one of them before each growing season. The selected quadrates within grazing plots were protected with cages. Although this method overlooks potential plant compensatory growth in response to grazing or mowing within the sampled growing season, the compensatory growth is limited under light and moderate intensity of grazing (Irisarri et al. 2016; Milchunas et al. 2008). Thus, we believe the ANPP measurements are representative of this system. In early August, all green plant tissues within selected quadrats were harvested, oven dried and weighed to obtain ANPP. To measure BNPP, we first took three soil cores $(7 \mathrm{~cm}$ in diameter) of $0-50 \mathrm{~cm}$ along the diagonal of each subplot at the end of growing season in 2017, sieved ( $2 \mathrm{~mm}$ mesh) soils to remove roots and refilled soil cores with root-free soils collected from the same depth. During the following two years (2018 and 2019), we resampled soils from the same cores at the same time of ANPP measurement, sieved ( $2 \mathrm{~mm}$ mesh) soil samples to obtain roots, oven dried and weighed them to calculate BNPP. Residual root-free soils were put back for BNPP measurements the next year.

In early August of 2019, we sampled three additional soil cores along the diagonal of each precipitation amount treatment subplot and measured microbial biomass carbon (MBC) and nitrogen (MBN) using the chloroform fumigation-extraction method (Vance et al. 1987). Specifically, we mixed three cores of soils collected from the same subplot, sieved ( $2 \mathrm{~mm}$ mesh) to remove plant tissues, and then weighed 6 aliquots ( $3 \mathrm{~g}$ equivalent). Subsequently, 3 of them were fumigated with ethanol-free $\mathrm{CHCl}_{3}$ at $25^{\circ} \mathrm{C}$ in the darkness for $48 \mathrm{~h}$ and the other 3 aliquots were unfumigated. The fumigated and unfumigated samples were extracted with $0.5 \mathrm{M} \mathrm{K}_{2} \mathrm{SO}_{4}(12 \mathrm{ml})$ for 30 min on a shaker. Carbon and nitrogen in the $\mathrm{K}_{2} \mathrm{SO}_{4}$ extracts were analyzed with a total organic $\mathrm{C} / \mathrm{N}$ analyzer (Elementar vario TOC, Elementar Co., Germany) and the differences between fumigated and unfumigated samples were converted to MBC and MBN with a conversion factor of 0.45 (Brookes et al. 1985; Liu et al. 2009).

\section{Statistical analysis}

In our statistical analyses, measured abiotic (i.e. ST and SM) and biotic (i.e. ANPP, BNPP, MBC and MBN) driving factors of respiration (or their annual mean values) were directly used in analyses, while $R_{S}$ and its components $\left(R_{h}\right.$ and $\left.R_{a}\right)$ were first natural logarithm transformed and then analyzed. Specifically, we analyzed the effects of precipitation and land use treatments on ST, SM, $R_{S}$ and its components $\left(R_{h}\right.$ and $R_{a}$ ) as well as annually measured plant and soil microbial parameters (ANPP, BNPP, MBC and MBN) using 
linear mixed-effects models. In these models, treatments of precipitation amount, land-use regimes, and date (or year for ANPP and BNPP) of measurement were treated as categorical fixed effects, and block,

plot and subplot were hierarchically arranged as random effects. The effects of treatments were analyzed in each year separately as well as combined over the 3-year study period (MBC and MBN were measured and analyzed only in 2019). Subsequently, we used structural equation models (SEMs) with annual mean values of variables to quantify direct and indirect impacts of abiotic (ST and SM) and biotic (plant and soil microbial parameters) factors on heterotrophic and autotrophic components of $R_{s}$. We first constructed initial SEMs including all potential paths based on theoretical knowledge (Liu et al. 2009; Geng et al. 2012; Xu et al. 2015; Chen et al. 2016) of driving factors of $R_{a}$ and $R_{h}$ (see Figure S4-S6 for details of examining driving factors with linear relationships). Subsequently, we performed a model selection of SEMs with the Chi-square () difference test (a good fit with a small and $P>0.1$ ), the goodness-of-fit index (GFl; a good fit when GFI > 0.90) and the root mean-square error of approximation (RMSEA; a good fit when RMSEA < 0.10) (Kline 2005) to obtained final SEMs. In SEMs, all variables were standardized to facilitate ease of interpretation and comparison.

All statistical analyses were conducted using R 3.6.3 (R Core Team 2013). We used lavaan package for SEMs and ggplot2 package to produce figures. Effects were considered statistically significant if $P<0.05$ or marginally significant if $0.05 \leq P<0.10$.

\section{Results}

\section{Effects of precipitation and land use on abiotic environment}

Precipitation amount significantly affected growing-season ST either in different years or over the 3-year study period (Figure 2a-d, Table S1). The growing-season ST increased by $0.56{ }^{\circ} \mathrm{C}$ under the dry treatment and decreased by $0.49{ }^{\circ} \mathrm{C}$ under the wet treatment on average over the three year. We did not observe significant effects of land-use regime and its interaction with precipitation amount on ST (Figure 2a-d, Table S1). For SM, it had been significantly impacted by precipitation amount and land use as well as their interaction in the overall study period (Figure $2 e-h$, Table S1). For precipitation amount treatments alone, growing-season SM decreased by $22.3 \%$ and increased by $30.5 \%$ on a 3 -year average under dry and wet treatments, respectively (Figure $2 \mathrm{~h}$ ). The effect of wet treatment was less pronounced under mowing. Compared with fencing, grazing and mowing under ambient precipitation, dry treatment respectively decreased SM by $24.0 \%, 22.9 \%$ and $20.4 \%$ and wet treatment respectively increased SM by $38.6 \%, 36.4 \%$ and $17.8 \%$ (Figure $2 \mathrm{~h}$ ). For land use treatments alone, grazing and mowing treatments respectively increased SM by $8.8 \%$ and $7.1 \%$ on a 3-year average compared with fencing (Figure $2 \mathrm{~h}$ ). When separately investigated in different years, the SM was only significantly impacted by precipitation amount in each year and significantly or marginally significantly affected by land-use regime and its interaction with precipitation amount in certain years (Figure 2e-g, Table S1).

Effects of precipitation and land use on above- and below-ground productivity 
Precipitation amount significantly influenced ANPP, showing a decrease of $72.4 \%$ and an increase of $47.4 \%$ on average over the three years under dry and wet treatments, respectively (Figure 2l, Table S1). The direction of the precipitation effect is consistently across the years and can all be detected statistically when data from each year were analyzed separately (Figure $2 \mathrm{i}-\mathrm{k}$, Table S1). Land-use regime alone had significant effects on ANPP in certain years (Figure $2 \mathrm{i}-\mathrm{k}$, Table S1), but had no effect on ANPP when integrated over the 3-year period (increased by $6.0 \%$ and decreased by $11.6 \%$ under grazing and mowing, respectively) (Figure 2I). In addition, we detected a marginally significant interaction between precipitation amount and land-use regime in 2018 as the effect of wet treatment was less pronounced under mowing. Compared with fencing, grazing and mowing under ambient precipitation, dry treatment respectively decreased ANPP by $70.7 \%, 90.3 \%$ and $82.4 \%$, while wet treatment respectively increased ANPP by $72.1 \%, 85.4 \%$ and $25 \%$ (Figure $2 \mathrm{j}$ ). The BNPP was significantly affected by precipitation amount and land-use regime but not by their interaction when separately considered in different years or integrated over the study period (Figure 2n-p, Table S1). Specifically, dry and wet treatments respectively resulted in a decrease of $16.1 \%$ and an increase of $14.3 \%$ in BNPP, while grazing and mowing respectively reduced BNPP by $11.7 \%$ and $1.0 \%$ on average over the study period (Figure $2 p$ ).

For the soil microbial community, precipitation amount significantly impacted MBC and MBN, while landuse regime only significantly impacted MBC (Figure 3, Table S1). Specifically, MBC and MBN were respectively reduced by $17.8 \%$ and $24.4 \%$ under dry treatment and respectively increased by $4.1 \%$ and 9.9\% under wet treatment (Figure 3). Compared with fencing, grazing decreased MBC by $5.5 \%$ and increased MBN by 4.5\%, while mowing increased MBC by $8.9 \%$ and increased MBN by $9.2 \%$ (Figure 3 ). We also detected significant or marginally significant interactive effects of precipitation and land use on $\mathrm{MBC}$ and $\mathrm{MBN}$ as the more pronounced dry effects under grazing (Figure 3). For MBC, dry treatment respectively decreased it by $10.3 \%, 33.0 \%$ and $10.4 \%$ under fencing, grazing and mowing compared with those of ambient precipitation, while wet treatment respectively increased it by $0.7 \%, 4.3 \%$ and $7.1 \%$ (Figure 3a). For MBN, dry treatment respectively decreased it by $8.0 \%, 48.8 \%$ and $14.5 \%$ under fencing, grazing and mowing compared with those of ambient precipitation, while wet treatment respectively increased it by $0.2 \%, 21.4 \%$ and $6.9 \%$ (Figure $3 b$ ).

\section{Effects of precipitation and land use on soil respiration and its components}

Precipitation amount significantly impacted $R_{S}$ and its components in different years and the overall study period (Figure 4, Table S2). On a 3-year average, $\mathrm{R}_{\mathrm{S}}$ and its autotrophic and heterotrophic components were reduced by $35.9 \%, 41.7 \%$ and $33.1 \%$ under dry treatment and increased by $28.5 \%$, $36.0 \%$ and $25.0 \%$ under wet treatment (Figure $4 \mathrm{~d}, \mathrm{~h}$ and $\mathrm{I}$ ). In addition, land use impacted $\mathrm{R}_{\mathrm{s}}$ and its components $\left(R_{a}\right.$ and $\left.R_{h}\right)$ across the three years (Figure $4 d, h, I$, Table S2). Compared with fencing treatment, grazing respectively reduced $R_{s}$ and $R_{a}$ by $1.1 \%$ and $5.3 \%$ but increased $R_{h}$ by $1.0 \%$, while mowing respectively reduced them by $7.2 \%, 10.7 \%$ and $5.5 \%$ on a 3 -year average. For the overall study period, precipitation and land use had no interactive impacts on $R_{s}$ and $R_{a}$, but interactively impacted $R_{h}$ with a marginal significance as wet treatment had a more pronounced impact under grazing (Figure 
4I). Compared with fencing, grazing and mowing under ambient precipitation, dry treatment respectively decreased $R_{h}$ by $31.9 \%, 33.5 \%$ and $34.0 \%$, while wet treatment respectively increased $R_{h}$ by $23.2 \%, 30.6 \%$ and $21.2 \%$ (Figure $4 I)$. In certain years, land use only significantly or marginally significantly impacted $R_{S}$ and $R_{h}$, but had no effect on $R_{a}$ (Figure $4 a-c, e-g, i-k$, Table S2). In addition, we also detected interactive effects of precipitation and land use on $R_{S}, R_{a}$ and $R_{h}$ in certain years (Figure $4 a, 4 f$ and $4 i$, Table $S 2$ ).

We then used SEMs to separately explore the direct and indirect effects of abiotic (ST and SM) and biotic (plant and soil microbial parameters) factors on $R_{a}$ and $R_{h}$ (see Figure $S 4-S 6$ for results of regressions used to construct initial SEMs as well as Figure S7 and Table S3-S4 for further details of initial SEMs). For $\mathrm{R}_{\mathrm{a}}$, our final SEM model confirmed positive direct influences of SM and BNPP, as well as a positive indirect impact of SM via BNPP and a negative indirect impact of ST via BNPP (Figure 5a, Table S5). In addition, the final SEM for $R_{h}$ confirmed positive direct impacts of $S M$ and MBN and a positive indirect impact of SM via MBN (Figure 5b, Table S6).

\section{Discussion}

We conducted a three-year manipulative experiment to investigate the effects of altered precipitation amount and land use regime on $\mathrm{R}_{\mathrm{s}}$ and its components. We found that increasing precipitation generally increases autotrophic, heterotrophic and total $R_{S}$, but the precipitation effect depends on land use regime. Despite previous studies on the precipitation effect (Liu et al. 2009, 2016; Hashimoto et al. 2015) or the land use effect (Liu et al. 2012; Han et al. 2012), quantification of their interactive effect remains rare. Our study highlighted the complex interactive effect of precipitation amount and land use on soil carbon fluxes through their influence on abiotic and biotic factors. We suggest that precisely predicting the consequence of climate change and land use should incorporate these interactions.

\section{Effects of precipitation amount and land-use regime on soil respiration and its components}

Our study found that precipitation treatment exerted a more substantial influence on soil respiration than land-use treatment (Figure 4). This is consistent with the observation that precipitation amount had stronger impacts on both soil moisture and soil temperature than land-use regime (Figure $2 a-h)$. The effects of precipitation on soil respiration is multifaceted. On the one hand, precipitation amount had positive effect on soil moisture (Figure $2 \mathrm{e}-\mathrm{h}$ ). High soil moisture due to precipitation increase presumably led to increase in $\mathrm{R}_{\mathrm{s}}$ and its components as observed in many previous studies (Liu et al 2009, Suseela et al 2012, Liu et al 2016). On the other hand, precipitation amount negatively impacted soil temperature (Figure 2a-d) due to energy dissipated as latent heat (Wan et al. 2007). Although low temperature would decrease soil respiration, such negative effect is outweighed by the positive effect of increased moisture, particularly in arid and semi-arid grasslands such as our study site (Fang et al 2015, Zhao et al 2015).

Plant and microbial regulation of soil respiration and its components 
The $R_{s}$ is composed of autotrophic $\left(R_{a}\right)$ and heterotrophic $\left(R_{h}\right)$ components, and is driven by both root and microbial activities (Bagchi and Ritchie 2010; Hou et al. 2014; Wang et al. 2020d). Our findings are consistent with this understanding as we observed strong impacts of soil moisture on plant primary productivities and microbial biomass $\mathrm{C}$ and $\mathrm{N}$. In particular, previous studies have shown that soil moisture can substantially affect $R_{h}$ (Liu et al. 2009, 2016; Suseela et al. 2012; Suseela and Dukes 2013; Chen et al. 2016; Tang et al. 2019; Wang et al. 2020c) via influencing either the growth of soil microbes or the diffusion of substrates to them (Schmidt et al. 2004; Hungate et al. 2007; Wang et al. 2020c). A previous precipitation manipulation experiment in our region found that increased soil moisture under high precipitation amount can improve the biomass of soil microbes, and therefore, stimulating $R_{h}$ and $R_{S}$ (Liu et al. 2009). This pattern is consistent with the current study. Moreover, our SEM model further showed that soil moisture had a stronger direct effect on $\mathrm{R}_{\mathrm{h}}$ than soil microbial biomass (nitrogen) (Figure $5 b$ ). This result suggests that the impact of soil moisture on substrate diffusion might be more important than its impact on microbial biomass in regulating $R_{h}$.

The $R_{s}$ can also be strongly regulated by plant productivity as a productive plant community can allocate more photosynthate to belowground, stimulating $R_{a}$ and thus $R_{s}$. At global and regional scales, previous studies have shown that $R_{s}$ can be positively impacted by precipitation and/or soil moisture because of their regulation on plant productivity (Geng et al. 2012; Peng et al. 2013), which is consistent with the current study (Figure $5 a$ ). In addition, the SEM for $\mathrm{R}_{\mathrm{a}}$ showed that the direct effect of BNPP on $\mathrm{R}_{\mathrm{a}}$ was as strong as that of soil moisture (Figure $5 a$ ). The regulation of BNPP on $R_{a}$ may result from the capacity of plants to physiologically adapt to water stress via adjusting stomatal conductance (Chaves 2002), changing the vertical distribution of roots and using groundwater of deeper soils (Jackson et al. 2000). For example, a recent 5-year precipitation manipulation experiment showed that decreasing precipitation amount by $50 \%$ results in more plant roots distributed in deeper soils (Liu et al. 2018). Because changing precipitation amount and land-use regime can influence plant community productivity via chronically shifting its structure in the long term (Xu et al. 2015; Liu et al. 2018), the discovered regulation of plant productivity on $R_{a}$ suggests that the long-term impacts of these changes on $R_{a}$ and $R_{S}$ may differ from the short-term impacts.

\section{Implications And Conclusions}

Our 3-year field experiment combining altered precipitation amount and land-use regime (Baoyin et al. 2014) showed that they can interactively affect $R_{s}$ and its components in certain years (Figure 4). The detected interactive impact is consistent with but weaker than a recent study in a meadow steppe of northeast China, showing persistent interactive effects of adding precipitation and a heaver intensity of grazing than ours on $R_{S}$ and its autotrophic component over a 2-year study period (Wang et al. 2020d). These results suggest that the interactive effects of precipitation and land use may be a general phenomenon in Inner Mongolian temperate grasslands. Thus, a precise prediction of ecosystems carbon cycling in response to climate change in this region should consider the land use context. As Inner 
Mongolian grasslands experience an increasing intensity in land use (Wu et al. 2015; Li et al. 2018; Wang et al. 2020a), future policies adapting to climate change should thus be coordinated with policies on land use.

\section{Declarations}

\section{Acknowledgements}

The authors thank Taogetao Baoyin, Hugjiltu Minggagud and other researchers and workers at the Grassland Ecosystem Research Station of Inner Mongolia University for helping maintain our experiment. This study was supported by the National Key Research and Development Program of China (2016YFC0500602), the National Natural Science Foundation of China (31971434, 32160274, 31960259 and 31600385), the Ministry of Science and Technology of China (2015BAC02B04) and the Natural Science Foundation of Inner Mongolia (2019MS03088, 2019MS03089 and 2015ZD05).

\section{Author contributions}

YW, FYL and WM designed the study. CZ, DW and WQ compiled the data. CZ produced the results and wrote the first draft with CS, BZ, YW and WM. All authors contributed to the development of the manuscript.

\section{Data availability statement}

The data that support the findings of this study are openly available in Figshare at https://doi.org/10.6084/m9.figshare.16974838.

\section{References}

1. Adams JM, Faure H, Faure-Denard L, Mcglade JM, Woodward FI (1990) Increases in terrestrial carbon storage from the last glacial maximum to the present. Nature 348:711-714

2. Bagchi S, Ritchie ME (2010) Introduced grazers can restrict potential soil carbon sequestration through impacts on plant community composition. Ecol Lett 13:959-968

3. Baoyin T, Li FY, Bao Q, Minggagud H, Zhong Y (2014) Effects of mowing regimes and climate variability on hay production of Leymus chinensis (Trin.) Tzvelev grassland in northern China. Rangel J 36:593

4. Bardgett RD, Jones AC, Jones DL et al (2001) Soil microbial community patterns related to the history and intensity of grazing in sub-montane ecosystems. Soil Boil Biochem 33:12-13

5. Brookes PC, Landman A, Pruden G, Jenkinson DS (1985) Chloroform fumigation and the release of soil nitrogen: a rapid direct extraction method to measure microbial biomass nitrogen in soil sciencedirect. Soil Biol Biochem 17:837-842 
6. Cao G, Tang Y, Mo W, Wang Y, Li Y, Zhao X (2004) Grazing intensity alters soil respiration in an alpine meadow on the Tibetan Plateau. Soil Biol Biochem 36:237-243

7. Carey JC, Tang J, Templer PH et al (2016) Temperature response of soil respiration largely unaltered with experimental warming. Proc Natl Acad Sci 113:13797-13802

8. Chaves MM, Pereira JS, Maroco J et al (2002) How plants cope with water stress in the field? Photosynthesis and growth. Ann Bot 89:907-916

9. Chen J, Luo Y, Xia J et al (2016) Differential responses of ecosystem respiration components to experimental warming in a meadow grassland on the Tibetan Plateau. Agric For Meteorol 220:21-29

10. Davidson EA, Janssens IA (2006) Temperature sensitivity of soil carbon decomposition and feedbacks to climate change. Nature 440:165-173

11. Fang J, Bai Y, Wu J (2015) Towards a better understanding of landscape patterns and ecosystem processes of the Mongolian Plateau. Landsc Ecol 30:1573-1578

12. Geng Y, Wang Y, Yang K, Wang S, Zeng H, Banumann F, Kuchn P, Scholten T, He JS (2012) Soil respiration in Tibetan alpine grasslands: belowground biomass and soil moisture, but not soil temperature, best explain the large-scale patterns. PLoS ONE 7:e34968

13. Gong J, Wang Y, Liu M, Huang Y, Yan X, Zhang Z, Zhang W (2014) Effects of land use on soil respiration in the temperate steppe of Inner Mongolia, China. Soil Tillage Res 144:20-31

14. Gossner MM, Lewinsohn TM, Kahl T et al (2016) Land-use intensification causes multitrophic homogenization of grassland communities. Nature 540:266-269

15. Han X, Owens K, Wu XB et al (2009) The grasslands of Inner Mongolia: a special feature. Rangel Ecol Manag 62:303-304

16. Han Y, Zhang Z, Wang C, Jiang F, Xia J (2012) Effects of mowing and nitrogen addition on soil respiration in three patches in an oldfield grassland in Inner Mongolia. J Plant Ecol 5:219-228

17. Hashimoto S, Carvalhais N, Ito A, Migliavacca M, Nishina K, Reichstein M (2015) Global spatiotemporal distribution of soil respiration modeled using a global database. Biogeosciences 12:4331-4364

18. Hou X, Wang Z, Michael SP, Ji L, Yun X (2014) The response of grassland productivity, soil carbon content and soil respiration rates to different grazing regimes in a desert steppe in northern China. Rangel J 36:573-582

19. Huang G, Li Y, Su Y (2015) Effects of increasing precipitation on soil microbial community composition and soil respiration in a temperate desert, northwestern China. Soil Biol Biochem 83:5256

20. Hungate BA, Hart SC, Selmants PC, Boyle SI, Gehring CA (2007) Soil responses to management, increased precipitation, and added nitrogen in ponderosa pine forests. Ecol Appl 17:1352-1365

21. IPCC (2013) Climate Change 2013: The Physical Science Basis: Working Group I Contribution to the Fifth Assessment Report of the Intergovernmental Panel on Climate Change. Cambridge University Press

Page $11 / 19$ 
22. Irisarri JGN, Derner JD, Porensky LM, Augustine DJ, Reeves JL, Mueller KE (2016) Grazing intensity differentially regulates ANPP response to precipitation in North American semiarid grasslands. Ecol Appl 26:1370-1380

23. Jackson RB, Sperry JS, Dawson TE (2000) Root water uptake and transport: using physiological processes in global predictions. Trends Plant Sci 5:482-488

24. Jia B, Zhou G, Wang F, Wang F, Wang Y, Weng E (2007) Effects of grazing on soil respiration of Leymus chinensis steppe. Clim Chang 82:211-223

25. Jia B, Zhou G, Wang Y, Wang F, Wang X (2006) Effects of temperature and soil water-content on soil respiration of grazed and ungrazed Leymus chinensis steppes, Inner Mongolia. J Arid Environ 67:60-76

26. Jing Z, Cheng J, Su J, Bai Y, Jin J (2014) Changes in plant community composition and soil properties under 3-decade grazing exclusion in semiarid grassland. Ecol Eng 64:171-178

27. Kline R (2005) Principles and practices of structural equation modeling, 2 edn. Guilford Press

28. Koncz P, Balogh J, Papp M et al (2015) Higher soil respiration under mowing than under grazing explained by biomass differences. Nutr Cycl Agroecosyst 103:201-215

29. Li J, Huang Y, Xu F, Wu L, Chen D, Bai Y (2018) Responses of growing-season soil respiration to water and nitrogen addition as affected by grazing intensity. Funct Ecol 32:1890-1901

30. Li Y, Zhou Z, Lei L et al (2020) Asymmetric responses of soil respiration in three temperate steppes along a precipitation gradient in northern China revealed by soil-monolith transplanting experiment. Agric For Meteorol 294:108-126

31. Liu H, Mi Z, Lin L et al (2018) Shifting plant species composition in response to climate change stabilizes grassland primary production. Proc Natl Acad Sci 115:4051-4056

32. Liu L, Wang X, Lajeunesse MJ et al (2016) A cross-biome synthesis of soil respiration and its determinants under simulated precipitation changes. Glob Chang Biol 22:1394-1405

33. Liu N, Zhang Y, Chang S, Kan H, Lin L (2012) Impact of grazing on soil carbon and microbial biomass in typical steppe and desert steppe of Inner Mongolia. PLoS ONE 7:e36434

34. Liu W, Zhang Z, Wan S (2009) Predominant role of water in regulating soil and microbial respiration and their responses to climate change in a semiarid grassland. Glob Chang Biol 15:184-195

35. Lu Z, Du R, Du P et al (2015) Influences of land use/cover types on Nitrous Oxide emissions during freeze-thaw periods from waterlogged soils in Inner Mongolia. PLoS ONE 10:e0139316

36. Luo Y (2007) Terrestrial carbon-cycle feedback to climate warming. Annu Rev Ecol Evol Syst 38:683-712

37. Ma Z, Liu H, Mi Z et al (2017) Climate warming reduces the temporal stability of plant community biomass production. Nat Commun 8:15378

38. Melillo JM, Frey SD, DeAngelis KM et al (2017) Long-term pattern and magnitude of soil carbon feedback to the climate system in a warming world. Science 358:101-105 
39. Milchunas DG, Lauenroth WK, Burke IC, Detling JK (2008) Effects of grazing on vegetation. Oxford University Press Inc

40. Musiał M, Kryszak J, Grzebisz W et al (2020) Effect of pasture management system change on inseason inorganic Nitrogen pools and heterotrophic microbial communities. Agronomy 10:724-745

41. Niu S, Wu M, Han Y, Xia J, Zhang Z, Yang H, Wan S (2010) Nitrogen effects on net ecosystem carbon exchange in a temperate steppe. Glob Chang Biol 16:144-155

42. Peng S, Piao S, Shen $Z$ et al (2013) Precipitation amount, seasonality and frequency regulate carbon cycling of a semi-arid grassland ecosystem in Inner Mongolia, China: a modeling analysis. Agric For Meteorol 178-179:46-55

43. Piao $S$, Ciais $P$, Huang $Y$ et al (2010) The impacts of climate change on water resources and agriculture in China. Nature 467:43-51

44. Piao S, Fang J, Ciais P et al (2009) The carbon balance of terrestrial ecosystems in China. Nature 458:1009-1013

45. R Core Team (2013) R: a language and environment for statistical computing. R Foundation for Statistical Computing

46. Ren C, Zhao F, Shi Z et al (2017) Differential responses of soil microbial biomass and carbondegrading enzyme activities to altered precipitation. Soil Biol Biochem 115:1-10

47. Schmidt IK, Tietema A, Williams D et al (2004) Soil solution chemistry and element fluxes in three European heathlands and their responses to warming and drought. Ecosystems 7:638-649

48. Suseela V, Conant RT, Wallenstein MD, Dukes JS (2012) Effects of soil moisture on the temperature sensitivity of heterotrophic respiration vary seasonally in an old-field climate change experiment. Glob Chang Biol 18:336-348

49. Suseela V, Dukes JS (2013) The responses of soil and rhizosphere respiration to simulated climatic changes vary by season. Ecology 94:403-413

50. Tang S, Wang K, Xiang Y et al (2019) Heavy grazing reduces grassland soil greenhouse gas fluxes: a global meta-analysis. Sci Total Environ 654:1218-1224

51. Vance ED, Brookes PC, Jenkinson DS (1987) An extraction method for measuring soil microbial biomass C. Soil Biol Biochem 19:703-707

52. Wan S, Hui D, Wallace L, Luo Y (2005) Direct and indirect effects of experimental warming on ecosystem carbon processes in a tallgrass prairie. Glob Biogeochem Cycles 19:GB2014

53. Wan S, Luo Y (2003) Substrate regulation of soil respiration in a tallgrass prairie: results of a clipping and shading experimen.Glob Biogeochem Cycles17. https://doi.org/10.1029/2002GB001971

54. Wan S, Norby RJ, Ledford J, Weltzin JF (2007) Responses of soil respiration to elevated $\mathrm{CO}_{2}$, air warming, and changing soil water availability in a model old-field grassland. Glob Chang Biol $13: 2411-2424$

55. Wang H, Liu H, Wang Y (2017) Warm- and cold- season grazing affect soil respiration differently in alpine grasslands. Agric Ecosyst Environ 248:136-143 
56. Wang W, Fang J (2009) Soil respiration and human effects on global grasslands. Glob Planet Chang $67: 20-28$

57. Wang X, Li FY, Tang K et al (2020a) Land use alters relationships of grassland productivity with plant and arthropod diversity in Inner Mongolian grassland.Ecol Appl30. https://doi.org/10.1002/eap.2052

58. Wang X, Li FY, Wang Y et al (2020b) High ecosystem multifunctionality under moderate grazing is associated with high plant but low bacterial diversity in a semi-arid steppe grassland. Plant Soil 448:265-276

59. Wang Y, Song C, Liu H, Wang S, Zeng H, Luo C, He J (2020c) Precipitation determines the magnitude and direction of interannual responses of soil respiration to experimental warming.Plant Soil. https://doi.org/10.1007/s11104-020-04438-y

60. Wang Y, Wang D, Shi B, Sun W (2020d) Differential effects of grazing, water, and nitrogen addition on soil respiration and its components in a meadow steppe. Plant Soil 447:581-598

61. Wu J, Zhang Q, Li A, Liang C (2015) Historical landscape dynamics of Inner Mongolia: patterns, drivers, and impacts. Landsc Ecol 30:1579-1598

62. Xu L, Baldocchi DD, Tang J (2004) How soil moisture, rain pulses, and growth alter the response of ecosystem respiration to temperature. Glob Biogeochem Cycles 18:GB4002

63. Xu X, Shi Z, Li D, Zhou X, Sherry RA, Luo Y (2015) Plant community structure regulates responses of prairie soil respiration to decadal experimental warming. Glob Chang Biol 21:3846-3853

64. Yang Z, Wei Y, Fu G, Song H, Li G, Xiao R (2020) Asymmetric effect of increased and decreased precipitation in different periods on soil and heterotrophic respiration in a semiarid grassland.Agric For Meteorol291. https://doi.org/10.1016/j.agrformet.2020.108039

65. Yvon-Durocher G, Caffrey JM, Cescatti A et al (2012) Reconciling the temperature dependence of respiration across timescales and ecosystem types. Nature 487:472-476

66. Zhao X, Hu H, Shen H, Zhou D, Zhou L, Myneni RB, Fang J (2015) Satellite-indicated long-term vegetation changes and their drivers on the Mongolian Plateau. Landsc Ecol 30:1599-1611

67. Zhong M, Song J, Zhou Z et al (2019) Asymmetric responses of plant community structure and composition to precipitation variabilities in a semi-arid steppe. Oecologia 191:697-708

68. Zhou G, Zhou X, He Y et al (2017) Grazing intensity significantly affects belowground carbon and nitrogen cycling in grassland ecosystems: A meta-analysis. Glob Chang Biol 23:1167-1179

69. Zhou X, Wan S, Luo Y (2007) Source components and interannual variability of soil $\mathrm{CO}_{2}$ efflux under experimental warming and clipping in a grassland ecosystem. Glob Chang Biol 13:761-775

70. Zhou Z, Wang C, Luo Y (2018) Response of soil microbial communities to altered precipitation: a global synthesis. Glob Ecol Biogeogr 27:1121-1136

\section{Figures}




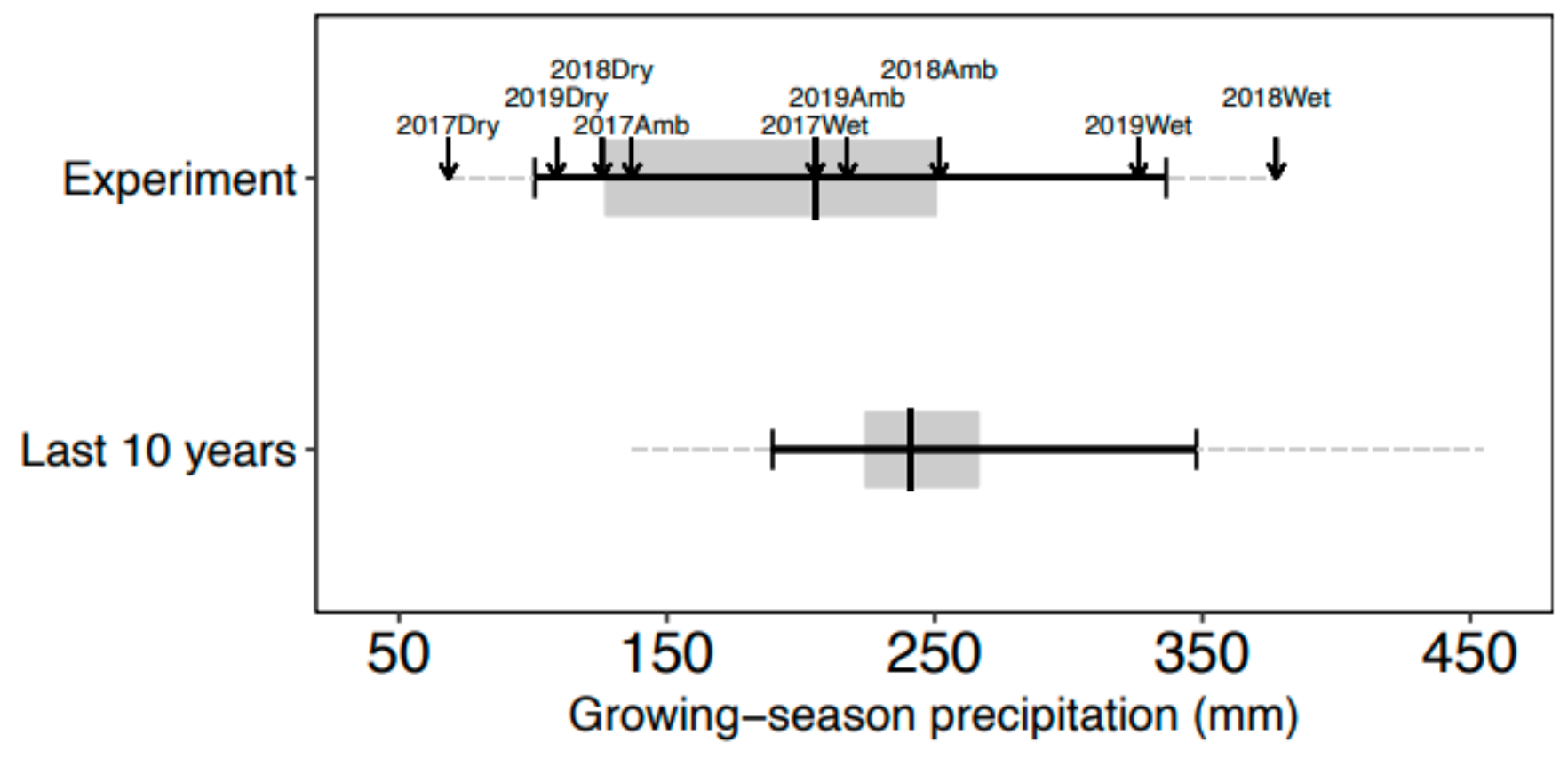

Figure 1

Box plots of growing-season precipitation in the in-situ experimental study and in the studied area over the last 10 years (2010-2019). The box plots show the medians (vertical solid black lines in the grey boxes), inter-quartile ranges (grey boxes), 10th and 90th percentiles (short black lines) and the minimum and maximum precipitation (dashed grey lines). Black arrows represent growing-season precipitation received by subplots of precipitation treatments (ambient growing-season precipitation $\pm 50 \%$ ). 

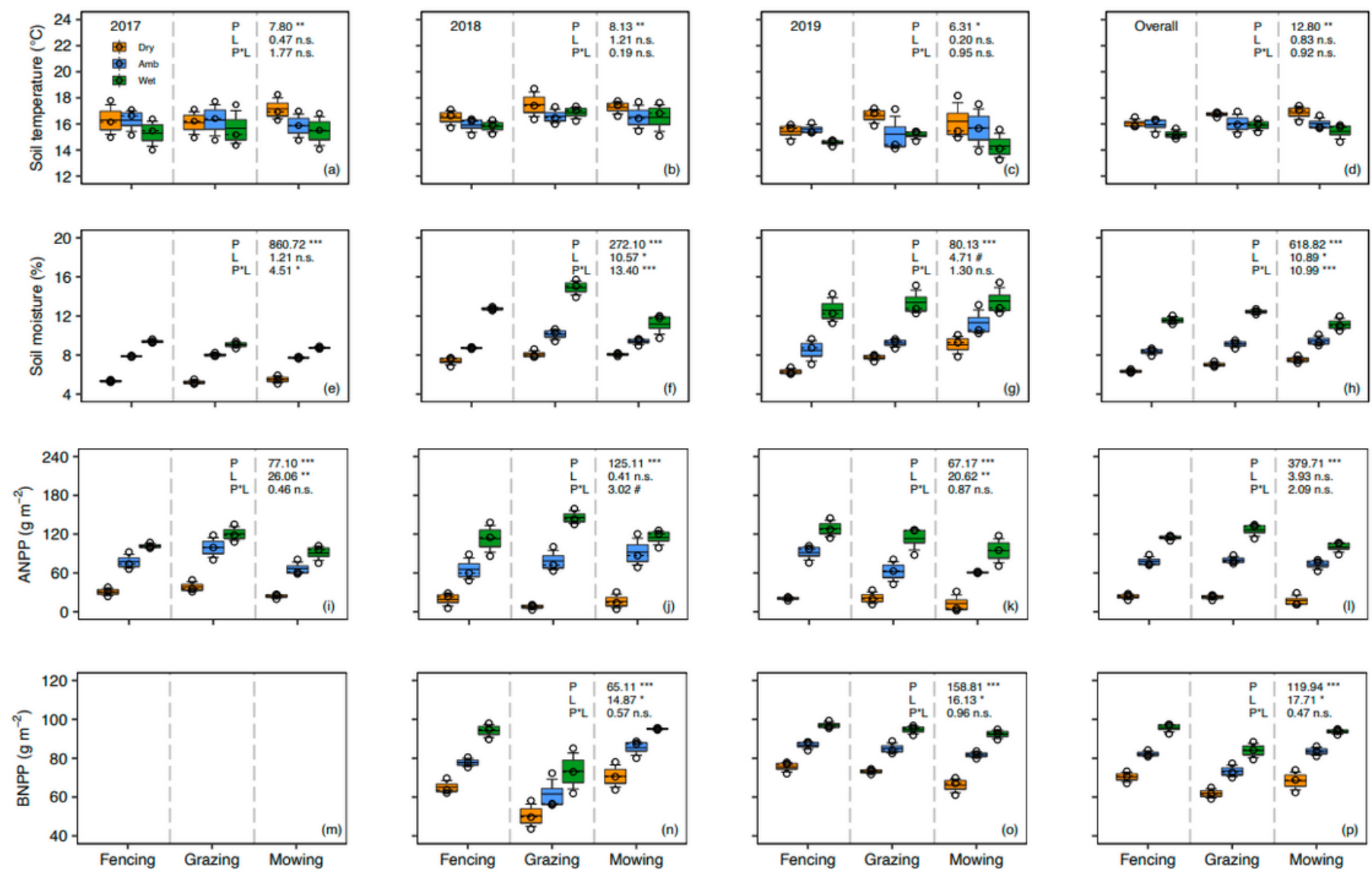

Figure 2

Effects of altered precipitation amount $(P)$ and land-use regime $(L)$ on soil temperature $(a-d)$ and moisture $(e-h)$ at $5 \mathrm{~cm}$ depth, aboveground (ANPP, $i-l)$ and belowground (BNPP, $n-p)$ net primary productivities. The box plots showed the mean and median (solid and dashed black lines in the boxes), interquartile ranges (boxes) and 10th and 90th percentiles (short black lines). Black cycles represent actual mean values. Results ( $F$ values) of the analysis of variance are shown in figure and indicated by

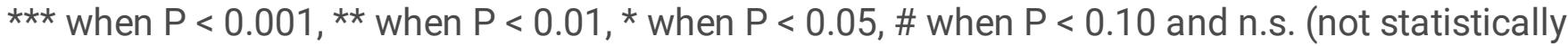
significant) when $P>0.10$. 

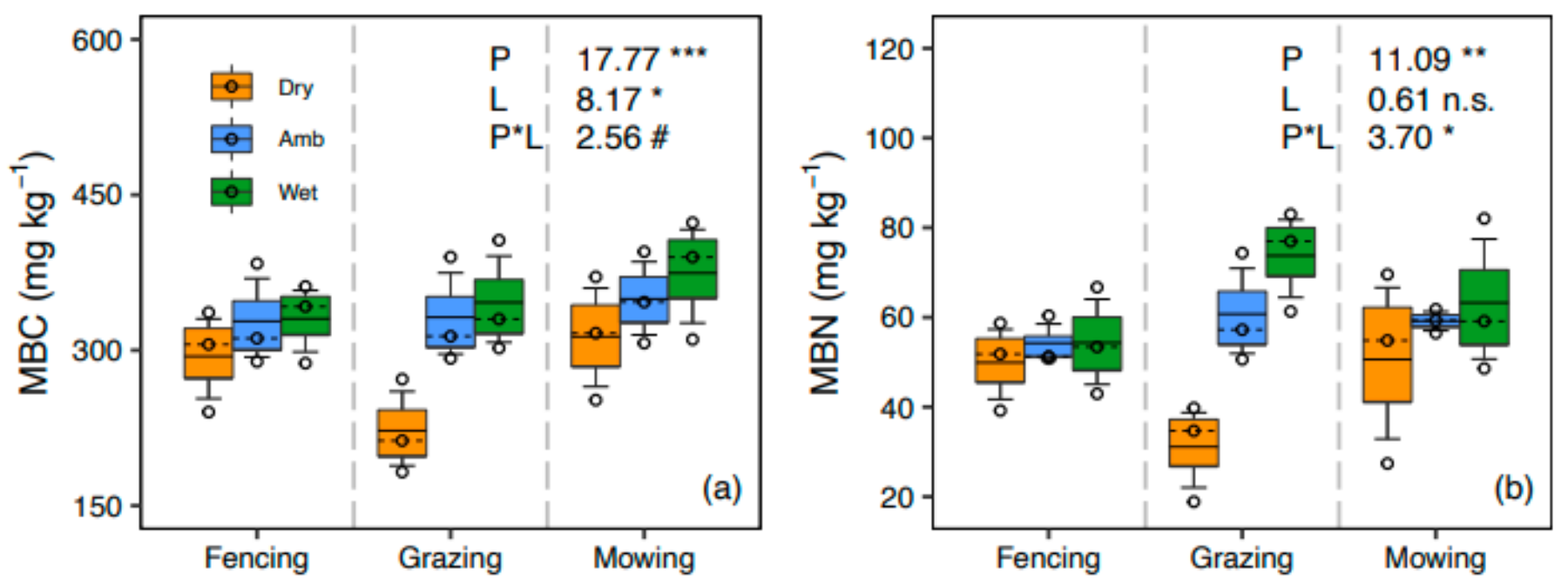

Figure 3

Effects of altered precipitation amount $(P)$ and land-use regime $(L)$ on soil microbial biomass carbon (MBC, a) and nitrogen (MBN, b). The box plots showed the mean and median (solid and dashed black lines in the boxes), interquartile ranges (boxes) and 10th and 90th percentiles (short black lines). Black cycles represent actual mean values. Results ( $F$ values) of the analysis of variance are shown in figure and indicated by *** when $\mathrm{P}<0.001$, ** when $\mathrm{P}<0.01$, * when $\mathrm{P}<0.05$, \# when $\mathrm{P}<0.10$ and n.s. (not statistically significant) when $\mathrm{P}>0.10$.
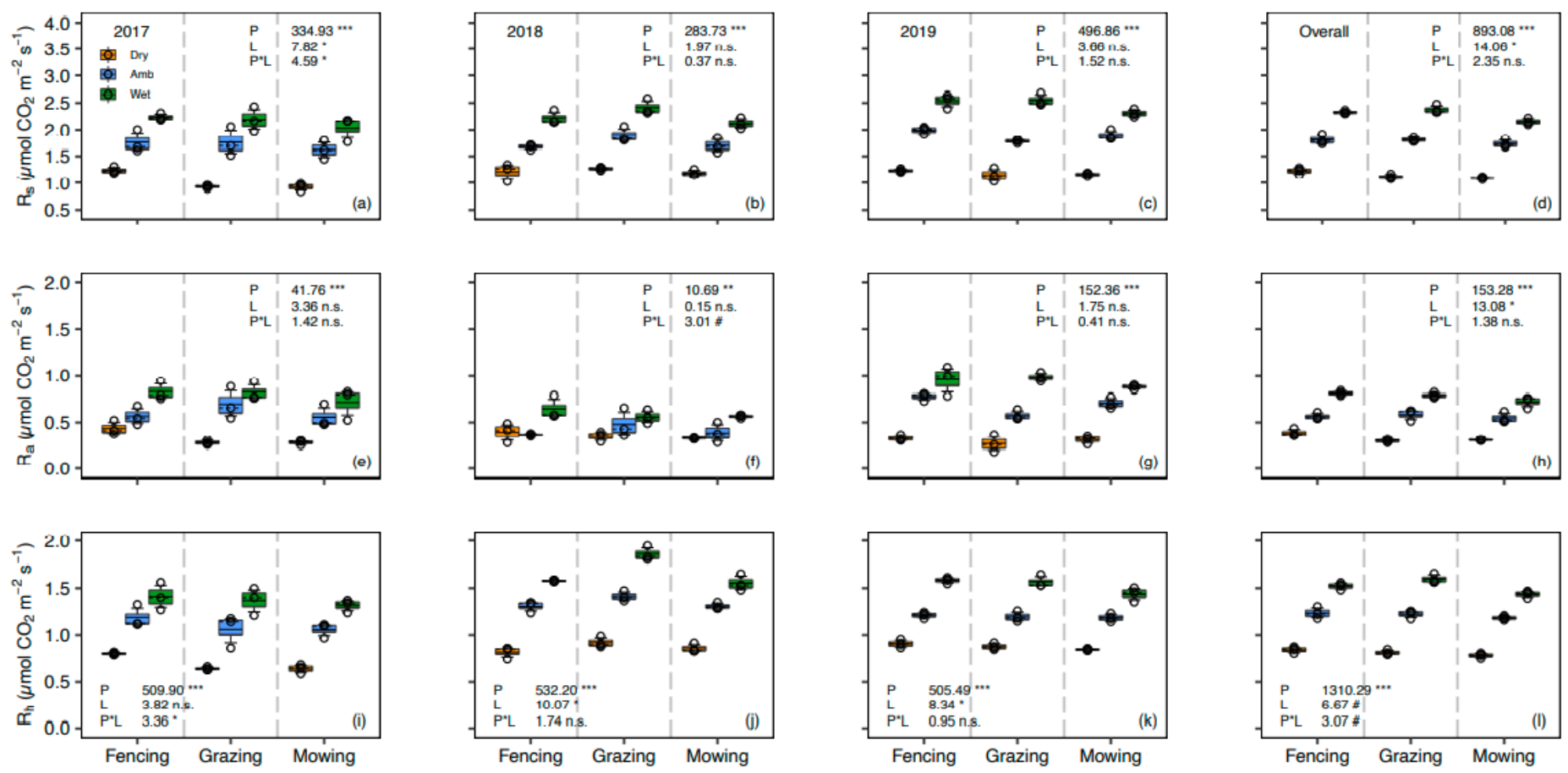

Figure 4 
Effects of altered precipitation amount $(P)$ and land-use regime $(L)$ on soil respiration (Rs, a-d) and its autotrophic $(\mathrm{Ra}, \mathrm{e}-\mathrm{h})$ and heterotrophic $(\mathrm{Rh}, \mathrm{i}-\mathrm{I})$ components. The box plots showed the mean and median (solid and dashed black lines in the boxes), interquartile ranges (boxes) and 10th and 90th percentiles (short black lines). Black cycles represent actual mean values. Results ( $F$ values) of the analysis of variance are shown in figure and indicated by *** when $P<0.001$, ** when $P<0.01$, * when $P$ $<0.05$, \# when $P<0.10$ and n.s. (not statistically significant) when $P>0.10$.

(a) $\chi^{2}=0.41, P=0.52 ; \mathrm{RMSEA}=0.00, \mathrm{GFI}=1.00$

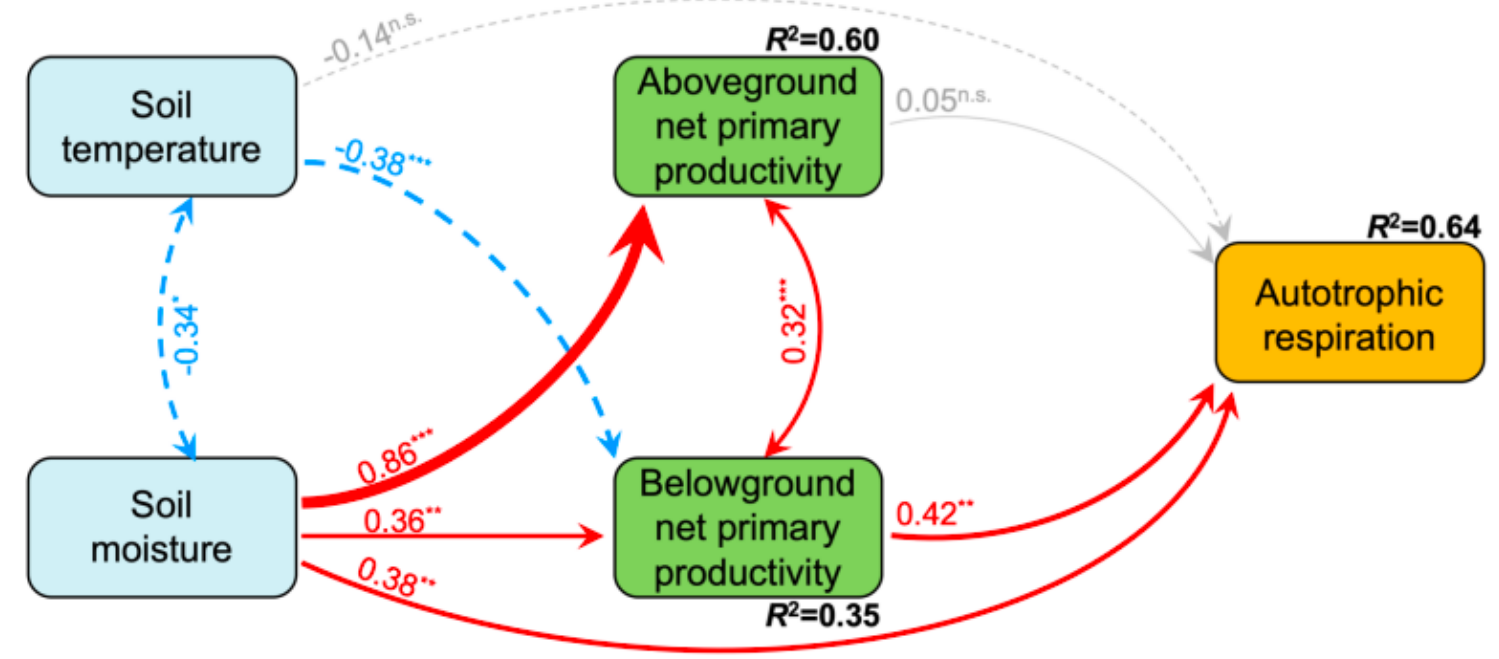

(b) $\chi^{2}=0.02, P=0.88 ;$ RMSEA $=0.00, \mathrm{GFI}=1.00$

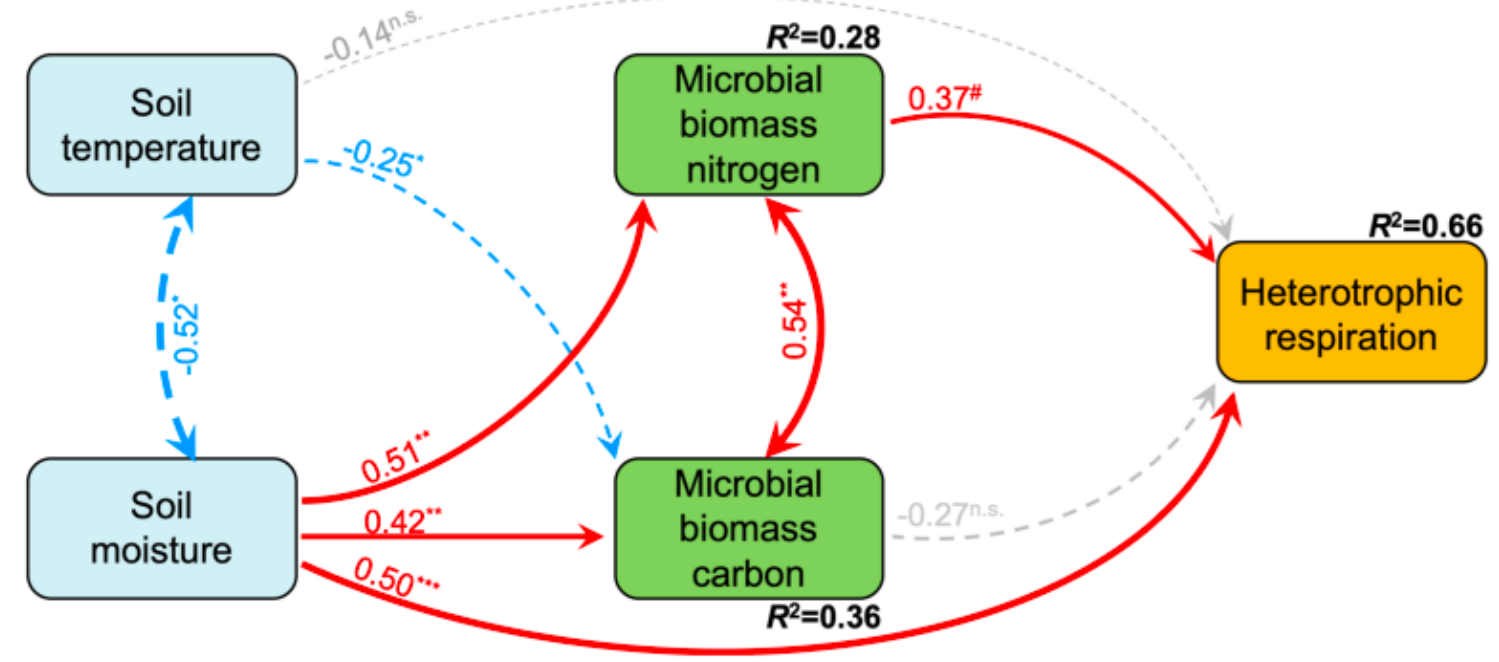

Figure 5 
Diagrams of final structural equation models (SEMs) for relating the autotrophic (a) and heterotrophic (b) components of soil respiration to their biotic and abiotic driving factors. All arrows are scaled in relation to the strength of the relationship, with numbers showing the standard path coefficients and indicated by *** when $\mathrm{P}<0.001$, ** when $\mathrm{P}<0.01$, * when $\mathrm{P}<0.05$, \# when $\mathrm{P}<0.10$ and n.s. (not statistically significant) when $P>0.10$. $R 2$ values are proportions of variance explained by dependent variables in the model. Model-fit statistics such as $\mathrm{X}$ 2-test, RMSEA and GFI are shown in each panel. Details of these SEMs can also be found in Table S5-S6. Details of initial SEMs can be found in Figure S7 and Table S3S4.

\section{Supplementary Files}

This is a list of supplementary files associated with this preprint. Click to download.

- V03.8CZIMSRSIWYH.docx 